\title{
On controlled switching of high voltage unloaded transmission lines ${ }^{1}$
}

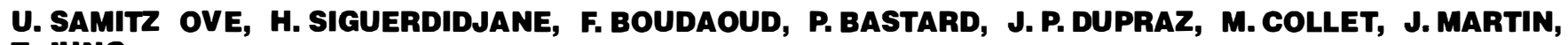 \\ T. JUNG
}

The limitation of switching overvoltages on very high voltage transmission lines is traditionally carried out with the aid of circuit breakers - fitted with closing resistors. This widely used system has repeatedly shown itself to be highly efficient. Nevertheless, it is possible to envisage other methods, in particular, those giving control of the circuit breaker instant of closing. This paper examines the possibilities offered by controlled switching on UHV transmission lines and compares existing solutions. It takes into account the various network characteristics that may be encountered. It details the results in terms of overvoltage levels which could be attained, due to the performance of the circuit breaker. The paper also highlights the critical points relative to the application.

Keywords: controlled switching; high voltage transmission line; shunt compensation; overvoltage; instrument transformers

\section{Synchronisiertes Schalten von ungeladenen Hochspannungsleitungen.}

Die Begrenzung von Schaltüberspannungen auf Höchstspannungsleitungen wird üblicherweise mit Leistungsschaltern mit angebauten Einschaltwiderständen erreicht. Dieses weitverbreitete System hat seine Wirksamkeit wiederholt bewiesen. Trotzdem gibt es auch andere Methoden, im Speziellen die Steuerung des Zuschaltaugenblicks des Leistungsschalters. Dieser Bericht untersucht die Möglichkeiten, die das synchronisierte Schalten von UHV-Leitungen bietet und vergleicht vorhandene Lösungen. Es werden die verschiedenen Netzzustände, die auftreten können, berücksichtigt. Der Bericht zeigt die Ergebnisse in Bezug auf erzielbare Überspannungsniveaus auf, die durch das Verhalten des Leistungsschalters erreicht werden können. Die kritischen Punke dieser Anwendung werden hervorgehoben.

Schlüsse/wörter: synchronisiertes Schalten; Hochspannungsleitung; Paralellkompensation; Überspannung; Messwandler

\section{Switching overvoltage}

A sudden change in the configuration of the electrical transmission network caused by the operation of a circuit breaker, or alternatively, by the appearance of a fault, can cause a rapid surge voltage known as a switching surge which propagates throughout the network. It is these switching overvoltages which, in general, determine the insulating requirements of the electrical transmission lines. The limitation of these overvoltages is of extreme importance, because they have an important effect on both the cost of transmission lines, and on their rate of failure.

These switching overvoltages can be manifest at both openIng and closing of circuit breakers. Given that the use of non-restriking circuit breakers is widespread, it is at the instant of closing, and above all, re-closing of a line which has held a trapped charge, that the strongest overvoltages appear.

Faced with this problem, the options chosen by the various operators of very high voltage networks throughout the world are varied. Up until recently, there have been two major alternatives.

(1) The networks that required limitation by means of a closing resistor, because without this limitation the level of insulation required for the lines would reach, or even exceed, $4 \mathrm{pu}$, which would make them economically unacceptable. Typically, these are the types of networks on which the operator uses three phase re-closing operations following a single phase fault, which implies numerous re-closings on lines holding a trapped charge. Thanks to this closing resistor, the overvoltage level is limited to a value of around 2 to $2.2 \mathrm{pu}$.

(2) The second alternative are networks that do not use a closing resistor, because the overvoltage level does not exceed $3 \mathrm{pu}$. These are typically networks on which the operator uses single phase re-closing. In this latter case, the vast majority of closings are carried out on lines that do not hold a trapped charge. This is the reason why the overvoltage does not exceed $3 \mathrm{pu}$. The percentage of re-closings on a line holding a trapped charge which could give rise to overvoltages superior to $3 \mathrm{pu}$ has been estimated at $1 \%$ (for bi-

SAMITZ, Ulrich, ALSTOM Austria AG, Kochlergang 14, A-4060 Leonding (e-mall: ulrıch.samitz@tde.alstom.com), SIGUERDIDJANE, Houria, Prof., BOUDAOUD, Farah, BASTARD, Patrick, Prof., SUPELEC, Service Electrotechnıque et Electronıque Industrielle, Plateau de Moulon, 3 rue Jolıot Curie, F.91190 Gif-surYvette, France, DUPRAZ, Jean-Pierre, COLLET, Michel, MARTIN Joseph, JUNG, Thierry, ALSTOM T\&D, 130 rue Léon Blum,

F-69100 Villeurbanne, France. 
phase faults or badly timed re-closings) and thus can be considered to be negligible (EDF-Direction).

For several years now, certain operators have had the tendency to replace the lımitation system using closıng resistors to one using phase-earth surge arresters. In certain cases, it can be sufficient that a surge arrester is located at both ends of the line to avoid exceeding the line's insulation level. Nevertheless, in general, one can say that, to obtain the same results as achieved using pre-insertion resistors, it is not only necessary that surge arresters are fitted to both ends of the lines, but they also have to be installed along the length of the line (Ribeiro, McCallum, 1989; Bladow, Weaver, 1990; Leroux et al., 1996; Eriksson, Grandl, Knudsen, 1990).

Could a controlled switching on the lines be a new method? What sorts of problems are caused by the use of such a system, and what are its limitations?

\section{Different types of UHV networks and their effects on controlled switching}

The reduction in overvoltages by using the controlled switching principle requires that the circuit breaker is re-closed at zero voltage across the circuit breaker terminals. Due to the various types of networks and operating methods, this condition can be easier, or harder, to satisfy.

\subsection{Uncompensated lines}

An uncompensated line is one without a shunt reactor. Thus, its particularity is that it remains charged after an opening. This trapped charge evolves according to atmospheric conditions (Beehler, 1964) and its real time measurement requires special voltage transformers, like mixed "resistor capacitor" dividers. Such equipment are very costly and seldom used. Hence, they will not be considered in the course of this paper. There are several other situations:

2.1.1 The line is fitted with Inductive Voltage Transformers on each phase. In this case, following an opening of the no-load line, the instrument transformer will rapidly discharge the line in less time than it takes for a re-closing (Marks, 1969). Therefore, all closings, or re-closings, will be on a discharged line. When using controlled switching, the closing target must be at zero of the source voltage, both for closings and re-closings. The simplest case to lend itself to controlled switching is that of the controlled switching of capacitor banks.

2.1.2 The line is fitted with Capacitive type Voltage Transformers, conventional or not, which will not discharge the line.

2.1.2.1 If the operation of the line uses three-phase re-closing, this means that all single-phase faults, which represent more than $90 \%$ of line faults, two phases will be re-closed onto trapped charges. The controlled operation should be dealt with differently depending on whether one is carrying out a closing operation on a discharged line or a re-closing. The trapped charge held by the line can evolve as a result of atmospheric conditions. As the capacitive voltage transformer cannot measure the evolution of the trapped charge, it is necessary to assess it. This assessment in some cases can be different from reality. It means that, in these cases, the overvoltages could be higher than calculated.

2.1.2.2 If the operation of the line uses single-phased re-closings, the number of cases in which the re-closing could be onto a trapped charge becomes extremely small and is limited to the cases of two-phase faults and untimely three phase re-closings. As stated in the second paragraph, if the insulation level of the line is $3 \mathrm{pu}$, the number of cases in which the overvoltages could exceed 3 pu durıng a two-phase fault or an untimely reclosing is somewhere in the order of $1 \%$ and thus, negligible. If one requires a lower level of insulation, in the order of $2 \mathrm{pu}$ for example, the percentage should be recalculated in order to ensure that it remains negligible. Depending on the results obtained, controlled switching on this type of line, using singlephase re-closing, should be either very simple because it is IImited to controlled switching on a simple closing or identical to that dealt with in the previous paragraph (see 2.1.2.1).

\subsection{Compensated lines}

Shunt reactor compensated lines are particular in the fact that, after opening, there is an oscillation at a frequency somewhere in the order of $50 \%$ to $90 \%$ of the network frequency. The voltage appearing across the circuit breaker terminals shows various degrees of fluctuation, depending on the degree of compensation. The optimal switching moment for re-closing is a minimum of the voltage beat.

The problematic network, that of single phase re-closing and three phase re-closing is the same as for the uncompensated lines. The major difference between this case and the previous, is that this time, the line voltage can be measured. One is thus capatole, theoretically, of using the correct algorithms, of determining the ideal instant to close the circuit breaker. Nevertheless, quite apart from the writing of the algorithm, there are still several difficulties linked to the accuracy of the instrument transformers when operating beyond their fundamental monitoring frequency. This can have an effect on the computational accuracy of the instant of circuit breaker re-closing, and thus, on the level of overvoltage attainable. With an efficient algorithm and good instrument transformers, the level of overvoltage will thus be governed by the closing, and not by the re-closing.

The level of shunt compensation for a line can vary from one instant to the next as a result of the power carried by the line. A line can thus be compensated at one instant but not at another, which causes a supplementary problem for the achievement of the controller.

\section{Simulations}

To study the various situations, numerous simulations have been run using EMTP/ATP network simulators.

\subsection{General network circuit diagram}

The simulated network is represented by the next Figures $1(a, b)$ :

\subsection{Models used and hypotheses}

The network models used are characterized by the following parameters:

$\begin{array}{ll}\text { Rated network voltage: } & 500 \mathrm{kV} \\ \text { Network frequency: } & 50 \mathrm{~Hz}\end{array}$

Source impedance, $\mathrm{Z} 1=0.5+25.1 \mathrm{ohm}$, chosen to produce a short circuit current of $10 \mathrm{kA}$.

The transmission line is a transposed three-phase line, $400 \mathrm{~km}$ long, with the following characteristics:

$\begin{array}{ll}\text { Zero-phase sequence resistance: } & 0.075 \mathrm{ohm} / \mathrm{km} \\ \text { Direct resistance: } & 0.025 \mathrm{ohm} / \mathrm{km} \\ \text { Zero-phase sequence inductance: } & 0.9 \mathrm{ohm} / \mathrm{km} \\ \text { Direct inductance: } & 0.3 \mathrm{ohm} / \mathrm{km} \\ \text { Zero-phase sequence capacitance: } & 6 \mathrm{nF} / \mathrm{km} \\ \text { Dırect capacitance: } & 14 \mathrm{nF} / \mathrm{km}\end{array}$

To measure the line side voltage of a circuit breaker, an Instrument transformer is fitted to each phase at the start of the line. Two types of transformers were modelled: 


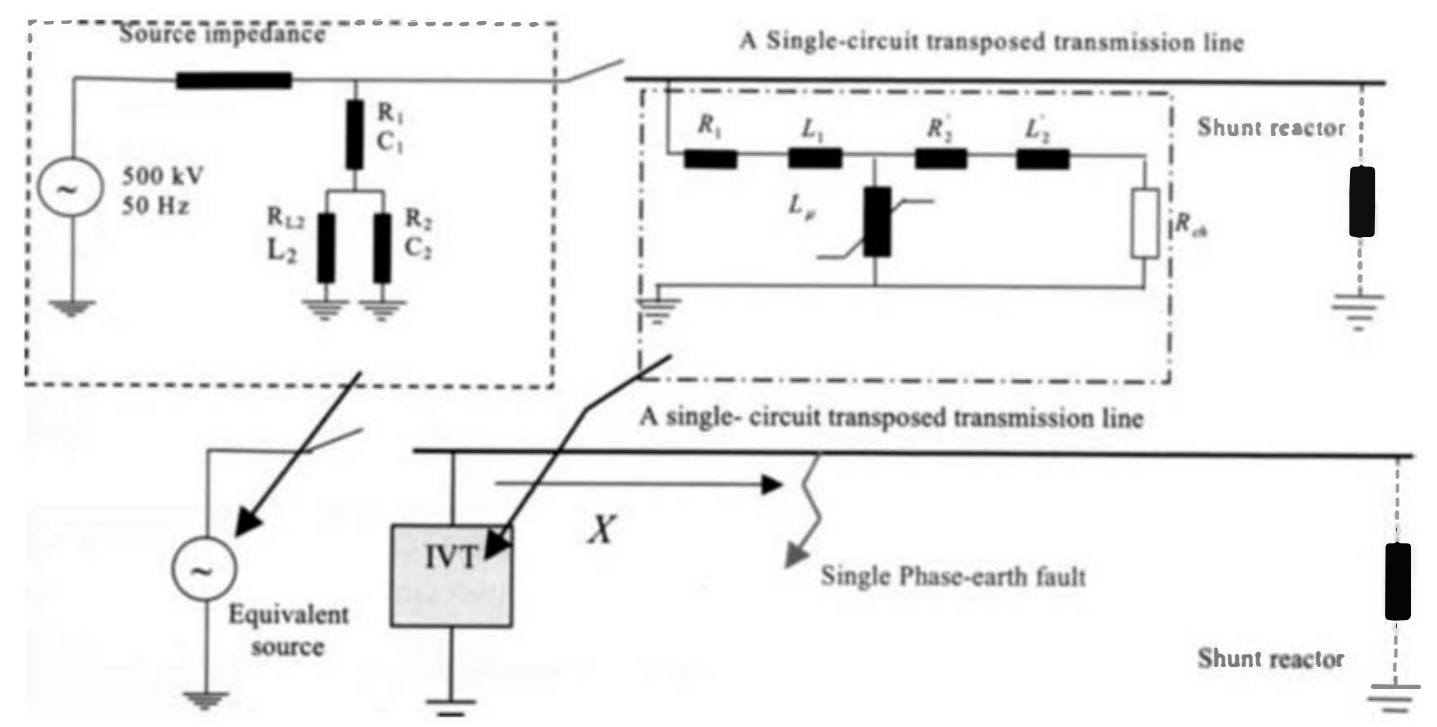

Fig. 1. (a) Uncompensated and shunt compensated line with single phase-earth fault and Inductive Voltage Transformer at the line side

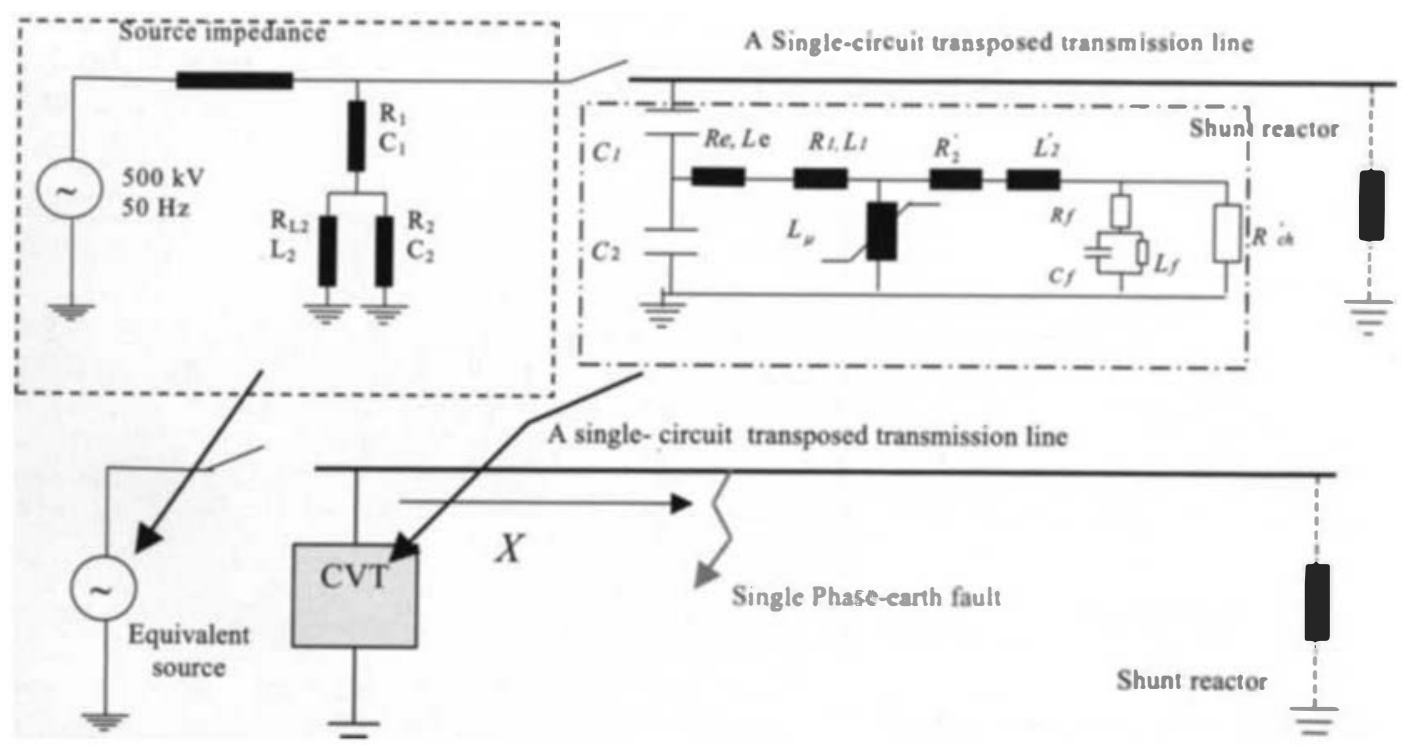

rig. 1. (D) uncompensatea ana snunt compensatea ıne witn sıngıe pnase-eartn tauıt ana capacılıe voıtage iransiormer at tne ıne sıae

(1) The Inductive Voltage Transformer (IVT), which can discharge the line, particularly in the case of an uncompensated no-load line.

(2) The Capacitive Voltage Transformer (CVT), which is more common with UHV circuits and which does not discharge the line and consists of a voltage divider in conjunction with an inductive transformer.

The study of compensated lines was carried out using two rates of compensation: $30 \%$ and $80 \%$.

For certain simulations, a surge arrester with a rated voltage of $420 \mathrm{kV}$ and a max. energy of $3.2 \mathrm{MJ}$ was fitted to the end of the line. The highest overvoltages observed appear some three quarters of the way down the line.

In the event of a three-phase re-closing, one considers, that there is a permanent mono-phase fault between Phase $A$ and earth, with a fault resistance of $R_{\text {fault }}=0$ (short circuit). This fault is located at the start of the line.

In order to take into account the closing time, the circuit breaker is modelled using the statistical model for an discon- necting switch. The variation in the closing times of the poles of the circuit breaker is presumed to follow a gaussian distribution, with a standard deviation, which will vary in the simulations between 0.25 and $1.5 \mathrm{~ms}$. A standard deviation of $0.25 \mathrm{~ms}$ means that $98 \%$ of the closing time is within a range of $\pm 0.6 \mathrm{~ms}$ of the mean value, which corresponds to a highly stable circuit breaker.

Within the simulations carried out, the circuit breaker assumed has a rate of decrease of dielectric strength (RDDS) of 1 $\mathrm{pu}$, thus covered by the pre-arcing times taken into account by these simulations.

\subsection{Algorithms}

Algorithms were developed for each network configuration detailed in the previous paragraphs (see 3.1, 3.2).

In the case of an uncompensated line with an IVT, the line voltage is discharged, both for the healthy phases, as well as for the faulty phase. For the normally operating phases, the voltage transformer is the path by which the trapped currents escape. For the faulty phase, the presence of the short circuit means that there is an exponential voltage discharge via the fault $\mathrm{Im}$ - 


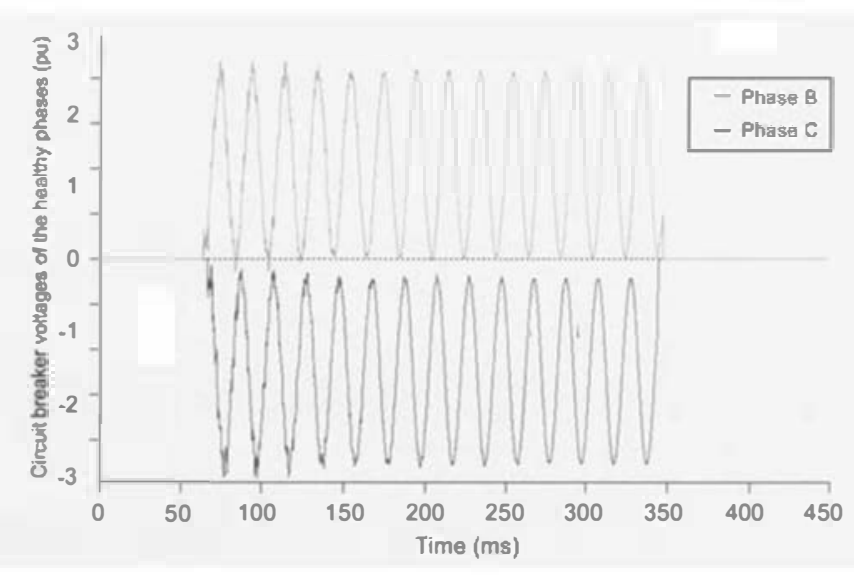

Fig. 2. Circuit breaker voltages for re-closing into uncompensated line with CVT-healthy phases

pedance. As from the instant the line side voltage reaches zero for each phase, the optimum re-closing time is identical to that of an standard controlled closing, given a zero voltage on the source side.

In the case of an uncompensated line with a CVT, the faulty phase is always discharged, due to the presence of the fault,

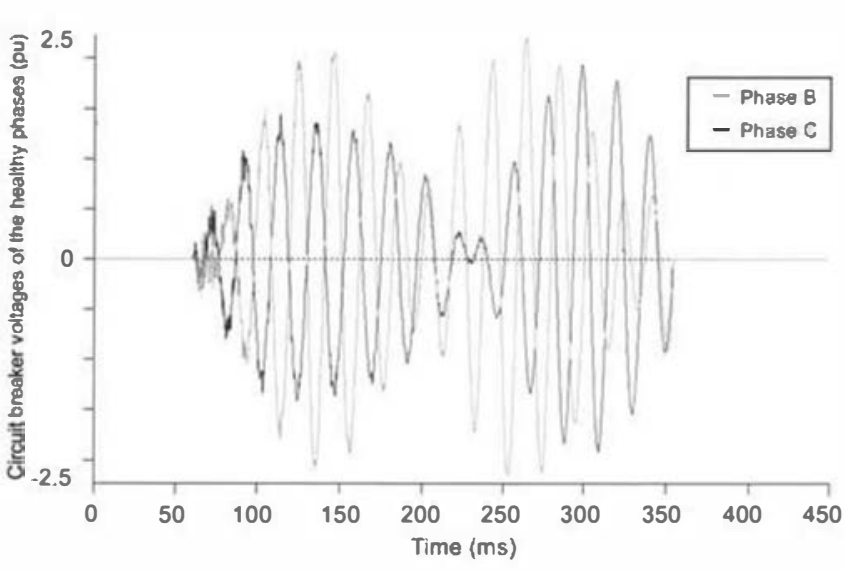

(a) $80 \%$ compensation degree

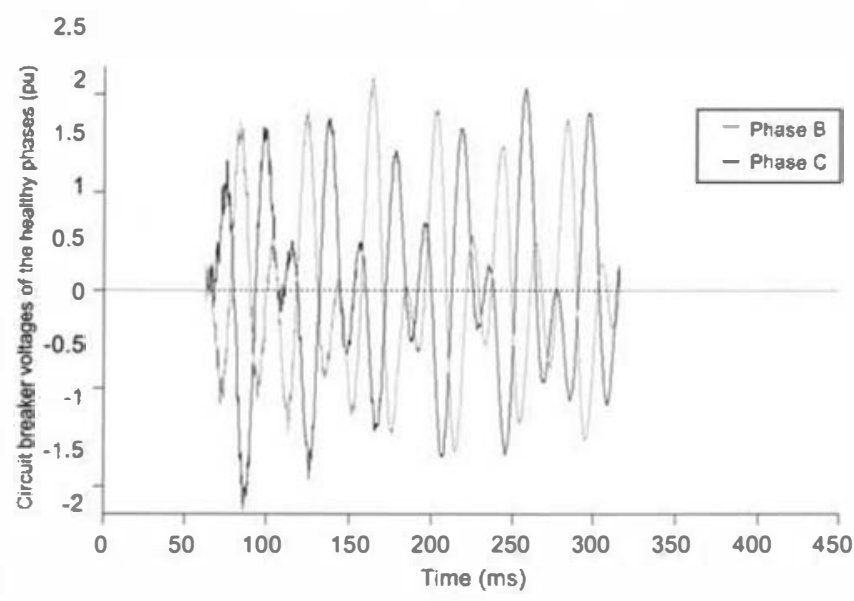

(b) $30 \%$ compensation degree

Fig. 3. Circuit breaker voltages-healthy phases

(a) $80 \%$ compensation degree,

(b) $30 \%$ compensation degree however, a trapped charge, assumed constant, can remain in the healthy phases. The optimum instant for re-closing is thus, for the latter examples, that of the minimum voltage across the circuit breaker terminals, which corresponds to the maximum voltage of same polarity on the source side (Fig. 2). This optimum instant is expressed as a function of the network frequency:

where $T=\frac{1}{f_{\text {source }}}$ or:

$$
t_{\text {close }}=t_{\text {open }}+K T
$$

$t_{\text {close }}$ Optimum instant for the closing of the poles of the working phases,

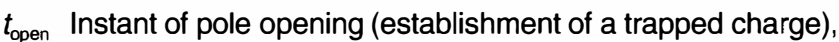

$T$ Source side Voltage penod

$K$ Number of cycles $T$ necessary for the re-closing of the working phases,

$f_{\text {source }}$ Network frequency.

In the case of a shunt compensated line with either an IVT or CVT, the line voltages across the healthy phases display, depending on the degree of compensation, varying degrees of fluctuation (Fig. $4 \mathrm{a}, \mathrm{b}$ ). The optimal window for the closing corresponds to the minimum fluctuation level of the voltage across the circuit breaker terminals for the phases in question (Fig. $3 a$,

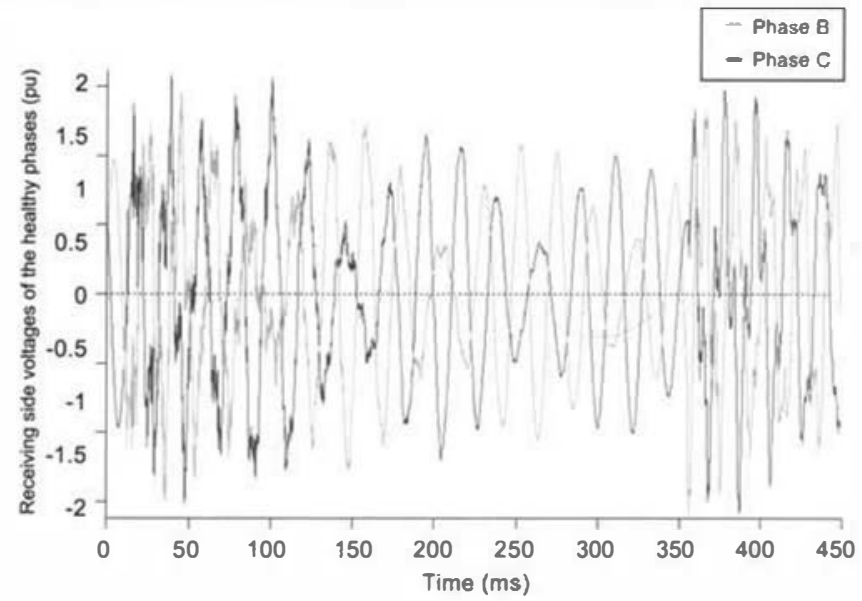

(a) $80 \%$ compensation degree

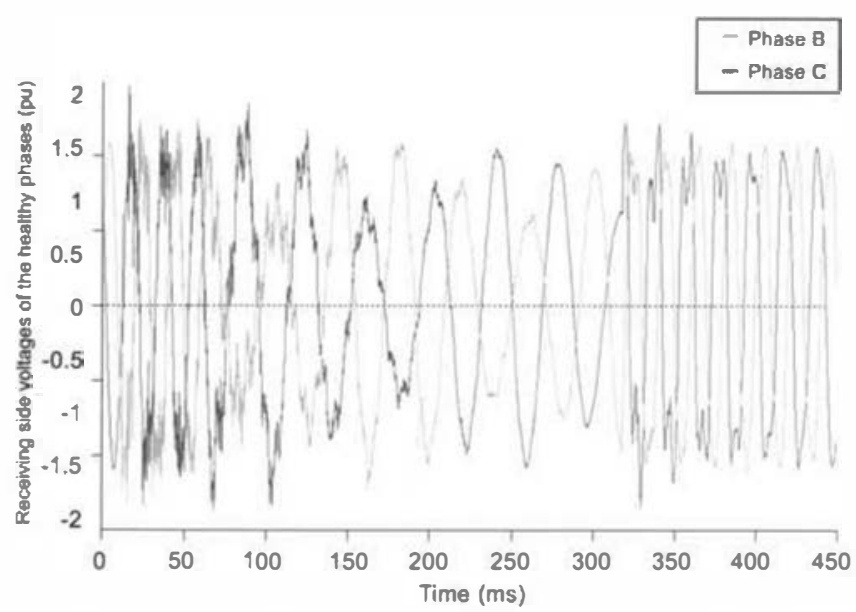

(b) $30 \%$ compensation degree

Fig. 4. Line voltages at the receiving side-healthy phases (a) $80 \%$ compensation degree (b) $30 \%$ compensation degree 
b). The dominant frequency $t_{\text {ine }}$ of the line voltage is principally related to the line capacity and the reactance of the shunt compensation.

. The equation for the optimal instant of re-closing is linked to the network frequency and the natural frequency of the line voltage, by means of:

$$
t_{\text {close }}=t_{\text {open }}+N T_{\text {cb }} \text {, }
$$

where $T_{\mathrm{cb}}=\frac{1}{f_{\text {source }}-f_{\text {line }}}$ or:

$t_{\text {close }}$ Optimum instant for the closing of the poles of the working phases,

$t_{\text {open }}$ Instant of pole opening (establishment of an oscillating trapped charge),

$T_{c b}$ Interval between two successive minimum fluctuation levels,

$N$ Number of cycles $T_{\mathrm{cb}}$ required for the re-closing of the working phases,

$f_{\text {source }}$ Network frequency,

$f_{\text {line }}$ Line side voltage frequency.

Concerning the faulty phase, the line voltage is subjected to, as in the previous case, an exponential discharge (Fig. 5). The optimum closing instant is that of the source side zero-voltage.

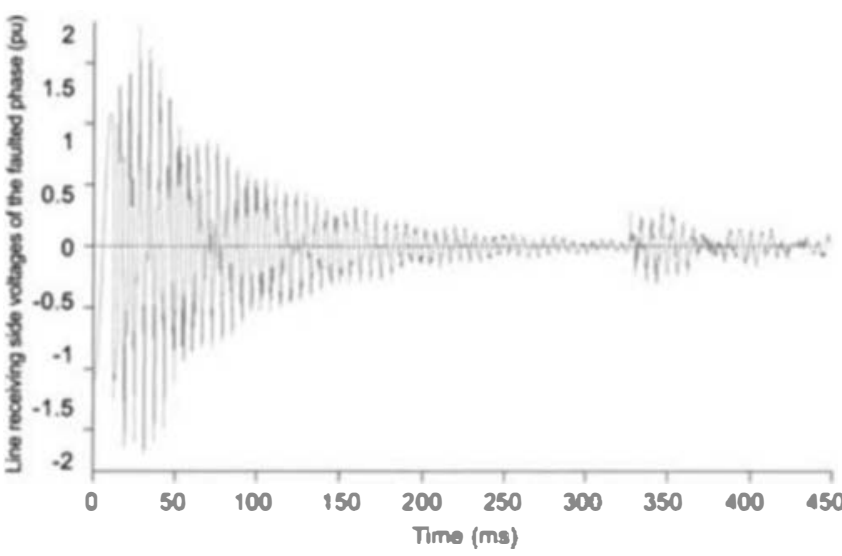

Fig. 5. Line recelving side voltage of the faulted phase $(30 \% \mathrm{com}$ pensation degree)

\subsection{Simulations carried out}

The simulations were carried out for each of the configurations detailed in the previous paragraph, with the network parameters as shown in 3.2, and the aforementioned circuit breaker characteristics.

In order to assess the influence on the accuracy of the circuit breaker closing time, $\mathbf{5 0 0}$ static tests were carried out on each of the optimum instants fixed by the algorithms. As well as that, the circuit breaker's pre-arcing time was taken into account.

These numerous simulations were carried out using an EMTP/ATP network simulator and an interface capable of generating the instant of closing automatically and then displaying the results obtained in terms of temporal voltage, current and overvoltage curves along the line.

The results of these simulations cannot be generalized, but nevertheless, show the order of magnitude expected from overvoltages on a $400 \mathrm{~km}$ long line. Taking into account the length chosen, one could consider that one is dealing with a difficult situation.
These simulations will essentially allow definition of the general tendencies for controlled switching of lines.

\subsubsection{Recapitulative tables and analyses}

Tables 1 to 4 show the principle results of the simulations carried out in terms of overvoltages obtained for various configurations as a function of the standard mechanical closing time deviation of the circuit breaker.

Table 1. Uncompensated lines

\begin{tabular}{llll}
\hline $\begin{array}{l}\text { Stand Dev. } \\
(\mathrm{ms})\end{array}$ & Closing & $\begin{array}{l}\text { Re-closing with an } \\
\text { IVT with a fault }\end{array}$ & $\begin{array}{l}\text { Re-closing with a } \\
\text { CVT with a fault }\end{array}$ \\
\hline 0.25 & 2.1 & 1.9 & 1.9 \\
0.5 & 2.3 & 2 & 19 \\
0.75 & 2.5 & 2.2 & 1.9 \\
1 & 2.7 & 2.3 & 1.9 \\
1.5 & 2.9 & 2.5 & 2.1 \\
\hline
\end{tabular}

Table 2. $80 \%$ compensated lines

\begin{tabular}{lll}
\hline $\begin{array}{l}\text { Stand Dev. of the mechanical tıme } \\
(\mathrm{ms})\end{array}$ & Closing & $\begin{array}{l}\text { Re-closing with } \\
\text { a fault }\end{array}$ \\
\hline 0.25 & 1.7 & 1.9 \\
0.5 & 2.0 & 1.9 \\
0.75 & 2.2 & 1.9 \\
1 & 2.3 & 1.9 \\
15 & 2.6 & 2.0 \\
\hline
\end{tabular}

Table 3. $30 \%$ compensated lines

\begin{tabular}{lll}
\hline $\begin{array}{l}\text { Stand. Dev. of the mechanical time } \\
(\mathrm{ms})\end{array}$ & Closıng & $\begin{array}{l}\text { Re-closıng with } \\
\text { a fault }\end{array}$ \\
\hline 0.25 & 2.3 & 1.9 \\
0.5 & 2.5 & 1.9 \\
0.75 & 2.7 & 1.9 \\
1 & 3.0 & 2.0 \\
1.5 & 3.2 & 2.1 \\
\hline
\end{tabular}

Table 4. $30 \%$ compensated lınes

\begin{tabular}{llll}
\hline $\begin{array}{l}\text { Stand Dev. of the } \\
\text { mechanical tıme }(\mathrm{ms})\end{array}$ & $\begin{array}{l}\text { Controlled } \\
\text { switching only }\end{array}$ & \multicolumn{2}{l}{$\begin{array}{l}\text { Controlled switching } \\
\text { and Surge arresters }\end{array}$} \\
\hline & $\mathrm{S}$ & $\mathrm{S}$ & $\mathrm{W}$ \\
0.25 & 2.3 & 2.1 & $<0.3$ \\
0.5 & 2.5 & 2.2 & $<0.4$ \\
0.75 & 2.7 & 2.2 & $<0.45$ \\
1 & 3.0 & 2.2 & $<0.6$ \\
1.5 & 3.2 & 2.2 & $<0.7$ \\
\hline
\end{tabular}

The following conclusions may be drawn from these simulations:

(1) The highest overvoltage levels are obtained during threephase closings and not for three-phase re-closings in the presence of a single-phase fault (Tables 1,2 and 3). This is due to the fact that the target window is much larger during a re-closing than during a simple closing. Moreover one sees that, in the case of re-closing in presence of single-phase fault, the maximum overvoltages often do not occur when reclosing the breaker but just after the inception of the fault. These results can only be held as valid if the algorithms, updated to include the re-closing target, are reliable and if the line voltages have been correctly measured. Within our simulations, we have assumed that the uncompensated line remains charged at its initial value and the compensated line voltage measurements were not subject to error. 
(2) The standard circuit breaker time variation is the most important variable parameter. The overvoltage level depends on it heavily if controlled switching is the only method used (no surge arresters) (Tables 1, 2 and 3).

(3) The influence of the rate of decrease of dielectric withstand (RDDS) has not been covered by this article due to the fact that it is of less importance than mechanical dispersion.

(4) Amongst the various studies carried out, the closing on a line with $30 \%$ compensation generated the highest levels of overvoltages (Table 3). A level of $2.3 \mathrm{pu}$ is attained using a circuit breaker, the standard deviation of which is only $0.25 \mathrm{~ms}$, which corresponds to an extremely accurate circuit breaker.

(5) The association of controlled switching and phase to earth surge arresters at the both ends of the line will limit the overvoltage levels to a suitable level, which depends much less on the circuit breaker's mechanical dispersion time than in the solution of the controlled switching alone (Table 4). In this case, the maximum overvoltage is located at a point three quarters of the way along the line. As the mechanical dispersion of the circuit breaker increases, the energy absorbed by the surge arrester also increases. Nevertheless, for a standard deviation of $1.5 \mathrm{~ms}$, which corresponds to a large dispersion value, the energy absorbed by the surge arrester, $420 \mathrm{kV}-3.2 \mathrm{MJ}$, will never exceed $70 \%$ of its rated value. This solution allows to combine the advantages of the controlled switching and the protection by surge arresters. It drastically reduces the influence of unavoidable variations in the operating time of the circuit-breakers during all their life time.

\section{The effect of controlled switching on equipment}

\subsection{Circuit breakers}

The simulations detailed above show that the use of controlled switching as the sole method for limiting overvoltages during unloaded line closing requires the use of circuit breakers with extremely stable closing time.

On the other hand, the solution using a combination of controlled switching and surge arresters should enable the use of standard circuit breakers.

\subsection{Measuring devices in the substation}

Controlled switching requires the installation of voltage transformers on all three phases of the line output, in addition to the information on at least one phase of the source voltage. The Inductive Voltage Transformers (IVT) allow a rapid discharge of an uncompensated line or the accurate measurement of the fluctuations in a compensated line, due to their large bandwidth.

Nevertheless, the price of IVTs becomes extremely high as the rated voltage increases, also the currently preferred transformers, Capacitive Voltage Transformers (CVT) are far more economical. These CVTs nevertheless have the disadvantage of a narrow bandwidth, due to the presence of a network frequency tuned circuit. As well as this, they do not allow trapped charges to escape from uncompensated lines, nor allow measurements to be taken of their level (information on the line side voltage is not indispensable however if one knows the exact instant of openıng for the pole and the source voltage: This information is sufficient for the determination of the level of trapped charges). In the case of a compensated line, the precision of the CVTs decreases in line with the decrease in the leve of line compensation. In fact, the frequency of the oscillating line load strays further from the network frequency as the degree of compensation decreases.

The use of CVTs with compensated lines should, in most cases, be preceded by a phase of sımulations in order to verify the validity of the results obtained.

What can be expected from non-conventional voltage transformers? Regardless of their technology, they neither discharge the line nor do they have significant influence on primary phenomenon, due to their low input capacitance. However, associated electronics provides a relatively flat frequency response at the vicinity of the rated frequency. Compared to CVTs, whose frequency response presents a resonance at the rated frequency, this is a significant advantage. Consequently, the transient response is more accurate and can be more easily modelled, allowing, for example, the storage of the trapped charge polarity resulting from the trip operation.

\subsection{Controlled switching devices}

The controlled switching devices available today are in the form of autonomous electronic boxes (often in 19" rack format), installed in relay buildings and used as individual protection equipment. Used for simple closing, a single source of information on the voltage of one phase on the source side is often sufficient for the calculation of the instant of controlled switching. These are pre-determined by the type of circuit breaker and load, with a few simple corrections due to influencing factors (temperature, circuit breaker pressure etc.) and to wear in the circuit breaker (altering the operating time).

The controlled switching devices used for on-line operations should be a little more sophisticated:

- acquisition of four sources of voltage information instead of one single source;

- increased calculating power required in order to determine the instant of re-closing when dealing with compensated lines. In fact, for this application, it is no longer a question of taking into consideration pre-establıshed controlled switching instants: Given that the degree of compensation varies with respect to the transitional power, the frequencies of oscillation on the line side can also change. Thus, one should always use algorithms designed to estimate the line side voltage sufficiently accurately and quickly in order that a command may be passed within the time limits laid down by the network control requirements (typically in the order of $300 \mathrm{~ms}$ ). Taking into account the mechanical operating time required by the circuit breakers, this would leave approximately $150 \mathrm{~ms}$ for the algorithm to estimate the frequency signals of between $25 \mathrm{~Hz}$ and $60 \mathrm{~Hz}$. This time budget is more than enough to perform this assessment with the required accuracy. Therefore there is no need to reduce the mechanical operating time of present circuit-breakers, as that parameter appears to be non-critıcal.

- Precise determination (with a level of accuracy below $0.5 \mathrm{~ms}$ ) for the instant of opening of the three poles of the circult breaker, in order to determine the levels of trapped charges in the case of uncompensated lines.

- Distınction between sımple closing and re-closing in the case of varying optimum instants of manoeuvre.

It is thus possible to envisage the evolution of such an online controlled switching application into a single device, communicating digitally with remote acquisition units (for the acquisition of orders and voltages). 


\subsection{The computational algorithm}

The applications for on-line re-closing need to be set up for the configuration of the network (levels of trapped charges and compensation). Apart from the problems due to the computing power, one should also pay particular attention to the sensitivity to "noise" of the algorithms in the estimation of the line side voltage.

The "noise" may come from various sources: harmonics, transients elther coming from the network or a non-linearity of the instrument transformer's transfer function, perturbations in the secondary transformer circuit cables, and finally, the noise generated intrinsically within the controlled switching device data acquisition chain. It is essential that one has an algorithm capable of determining the evolution of the compensated line side voltage in 'real time', within a few cycles. Designing this algorithm certainly represents the hardest part of controlled switching on no-load lines.

\section{Conclusion}

The wide variety of electrical networks and operational modes means that it is extremely difficult to generalize standardized conclusions. This is made even harder when one takes into consideration the number of simulations carried out (closıngs on compensated and uncompensated lines, with or without trapped charges, with IVT/CVT). We cannot simulate all possible situations. Nevertheless, taking our simulations as a starting point, which corresponds to the most difficult network conditions, we think that we are capable of stating a few clear principles.

The networks considered correspond to networks in which the circuit breakers used are traditionally fitted with closing resistors, which, limit the overvoltages to approximately 2 to $2.2 \mathrm{pu}$.

One sees that the exclusive use of controlled switching, without other devices, does not always lead to the achievement of the required overvoltage levels, even with extremely accurate circuit breakers. One could suppose that with such a solution, the operator would never be effected by the unavoidable variations in the operating time of circuit breakers during their thirtyyear life expectancy and also the possibilities of inaccuracies in the algorithms.

As a result of this, it seems necessary to us that phase-earth surge arresters at the ends of the line are systematically associ- ated with circuit breaker controlled switching, as a safety measure. With a standard network surge arrester, it is possible to limit the overvoltage to $2.2 \mathrm{pu}$, even with a circuit breaker with a mechanical time deviation of up to $\pm 3 \mathrm{~ms}$. Lower limitation levels can be achieved using high-performance surge arresters.

The choice of solution to be adopted should be the result of a technical-economic study of the three solutions, which are: closing resistors, the conjunction of controlled switching with surge arresters and finally the exclusive use of surge arresters.

(1) Firstly, a study of the network should enable one to define the parameters of the devices required in order to achieve the required overvoltage levels.

(2) Secondly, it will be necessary to compare the costs of investments and operation of the various solutions.

The investment costs are directly drawn from the technical study and are easily detailed. On the other hand, an estimation of the operating costs is much harder to establish accurately due to its dependence on the reliability of the equipment installed. It will be all the more difficult to estimate, as there is little operational experience of the solution in question.

\section{References}

Beehler, J. E. (1964): Weather, Corona, and the decay of trapped energy on transmission lines. IEEE PAS, May 1964: 512-520.

Bladow, J. K., Weaver, T. L. (1990): Contrôle des surtensions pour le projet de lıgne de transport $500 \mathrm{kV}$ Californie - Orégon. Cigré 1990: 13-304.

EDF-Direction des études et recherches, H112: La coordination d'ısolement du réseau à $400 \mathrm{kV}$.

Eriksson, A., Grandl, J., Knudsen, O. (1990): Contrôle optimisé des surtensions de manœuvres en lignes au moyen de disjoncteurs sans résistance de fermeture. Cigré 1990: 13-305.

Leroux, D., Breault, S., Dutil, A., Croteau, G. (1996): Utilisation de parafoudres sur les lignes à $735 \mathrm{kV}$ comme solutıon alternative de contrôle des surtensions de manœuvre. Validation par des essais en réseau. Conférence et Exposition Electricıté 96, Montréa 28 avril au 3 mai 96.

Marks, L. W. (1969): Line discharge by potentıal transformers. IEEE PAS, April 1969: 293-297

Ribeiro, J. R., McCallum, M. E. (1989): An applıcation of metal oxide arresters in the elımınatıon of need for closing resistors in EHV breakers. IEEE Transactions on Power Delıvery, Vol. 4, Nr. 1. 